\title{
Congenital tracheo-oesophageal fistula in the adult
}

\author{
ROBERT J BLACK
}

From Princess Alexandra Hospital, Brisbane, Australia

ABSTRACT A case of congenital tracheo-oesophageal fistula without oesophageal atresia in an adult is presented. Surgical repair via a right thoracotomy was successfully undertaken. The 13 previously reported cases in English publications are reviewed.

The majority of tracheo-oesophageal fistulae are diagnosed immediately after birth or during infancy. These are brought to light because of the lifethreatening complications of oesophageal atresia and inhalation of secretions. The purpose of this paper is to report a case of congenital tracheo-oesophageal fistula in an adult.

\section{Case report}

A 50-year-old woman presented in May 1977 with a history of chronic cough. She stated that episodes of coughing were worse when she dined out and were associated more with swallowing liquids than solids. She had a history of recurrent mild chest infections as a child. A barium swallow performed 25 years previously had been reported as normal but these films were not available.

Clinical examination revealed no abnormality. A barium swallow on this occasion revealed a fistula on the right side of the oesophagus communicating with the trachea. This was best demonstrated with the patient lying on her right side and partially prone. The barium passed into the right main bronchus and into the anterior segment of the right upper lobe (figure).

A bronchoscopy revealed that the fistula was directed caudally towards the oesophagus. The tracheal opening was $5 \mathrm{~cm}$ proximal to the carina. Oesophagoscopy failed to show the oesophageal opening.

In June 1977, via a right thoracotomy, the fistula was divided and oversewn and mediastinal tissue was interposed at the site of closure.

Address for reprint requests: 529 Old Cleveland Road, Camp Hill, Queensland 4152, Australia.
Two subsequent bronchoscopies have been performed for recurrence of cough. On each occasion, part of a silk stitch was found at the repair site and removed.

There has been no recurrence of the fistula and the patient is well. She eats a normal diet without difficulty.

\section{Discussion}

There are five main categories of congenital tracheooesophageal fistula and oesophageal atresia ${ }^{1}$ (table 1). The incidence of fistula without atresia varies and has been reported as ranging from $1.8 \%$ to $8 \cdot 3 \% \%^{1-3}$ This defect is a rare anomaly in infants and its persistence into adult life is indeed uncommon. The patient often presents with chronic lung disease of unknown aetiology.

There are 13 previously reported cases in English publications. The first was in $1929^{4}$ and was an incidental postmortem finding. The second case reported underwent no treatment, 5 and two later cases died from aspiration pneumonia. ${ }^{7}$ Subsequent cases have been successfully treated and are reported in table 2.8-16

The criteria for diagnosing the defect as congenital in origin are based on: (1) respiratory symptoms over many years; (2) histological evidence of epithelial lining of and some muscularis mucosae in the fistulous tract; (3) the absence of an aetiological factor-for example, inflammation, neoplasm,

Table 1 Classification by anatomical characteristics

\begin{tabular}{lc}
\hline Classification & Incidence (\%) \\
\hline Atresia without fistula & 9 \\
Atresia with proximal fistula & 1 \\
Atresia with distal fistula & 87 \\
Atresia with proximal and distal fistula & $1 \cdot 2$ \\
Fistula without atresia & $1 \cdot 8$ \\
\hline
\end{tabular}




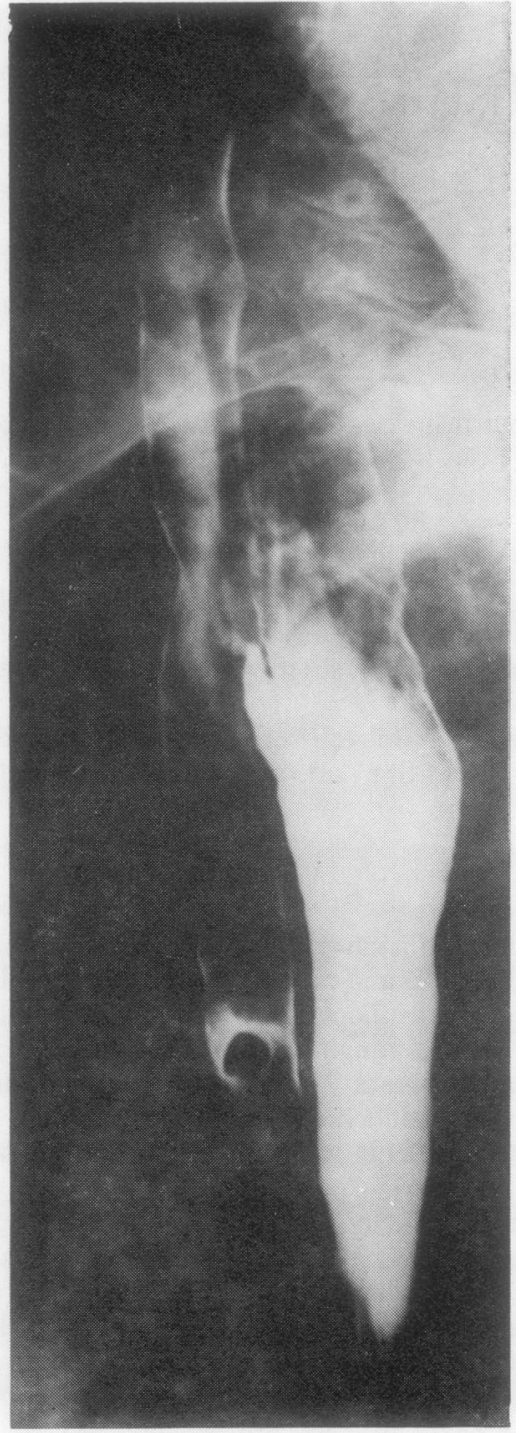

(a)

Figure Barium swallow demonstrating the tracheo-oesophageal fistula outlining the right main bronchus (a) and anterior segment of the right upper lobe $(b)$.

foreign body.

The patients' ages at the time of diagnosis have ranged from 15-63 years and there were equal numbers of males and females. Treatment has usually been closure via a thoracotomy.

A chronic cough and recurrent respiratory infections are almost always present ${ }^{15}$ and characteristically solid food is better tolerated than liquids. Increasing obliquity of the course of the

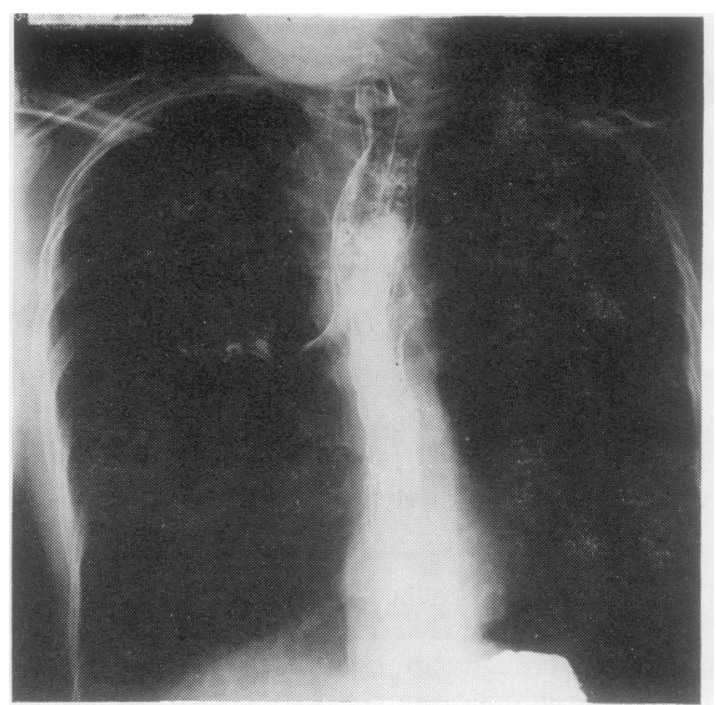

(b)

Table 2 Summary of reported cases of congenital tracheo-oesophageal fistula in adults

\begin{tabular}{llll}
\hline Author & Age $(y r)$ & Sex & Treatment \\
\hline Negus $(1929)^{4}$ & 45 & M & Died-carcinoma lung \\
McKinney $(1933)^{5}$ & 58 & F & Nil \\
Krausey $(1958)^{6}$ & 38 & F & Died-pneumonia \\
Caldwell $(1954)^{7}$ & 54 & M & Died-pneumonia \\
Mathey $(1954)^{8}$ & 16 & F & Thoracotomy repair \\
Demong $(1959)^{9}$ & 15 & F & $\begin{array}{l}\text { Pneumonectomy } \\
\text { repair }\end{array}$ \\
Ferguson $(1959)^{10}$ & 23 & F & Thoracotomy repair \\
Lansden $(1960)^{11}$ & 63 & F & Cervical repair \\
Zack $(1967)^{12}$ & 32 & M & Thoracotomy repair \\
Tenta $(1967)^{13}$ & 16 & M & Thoracotomy repair \\
Bertelsen $(1970)^{14}$ & 48 & M & Thoracotomy repair \\
Acosta $(1974)^{15}$ & 48 & M & Cervical repair \\
Stephens $(1976)^{16}$ & 26 & M & Thoracotomy repair \\
Present case & 50 & F & Thoracotomy repair \\
\hline
\end{tabular}

fistula with age (because of differential growth rates of the oesophagus and trachea) explains the trivial symptoms in early life and consequent progression of the undiagnosed defect into adulthood. ${ }^{16}$

Diagnostic confirmation of a fistula may be difficult. The surgeon must be aware of the possibility and contrast studies should demonstrate the fistula and not just reveal the presence of barium in the bronchial tree. With the rapid pharyngeal phase and upper oesophageal phase of swallowing, demonstration of a fistula may be difficult with conventional barium swallow examination. Cineradiography ${ }^{17}$ in the prone position ${ }^{18}$ with oblique views may be rewarding. Endoscopy is essential to exclude other pathology. It may not be possible to identify the oesophageal opening (as in this case) but contrast material or a catheter passed from the tracheal orifice will assist. If fibreoptic broncho- 
scopy is performed under general anaesthesia with an endotracheal tube the tracheal opening may be missed, so thorough examination of the trachea with a rigid bronchoscope is advised.

Congenital tracheo-oesophageal fistula without atresia is commonly known as the " $\mathrm{H}$ " type defect, indicating direct communication. ${ }^{16}$ As stated earlier, the opening in the trachea is usually situated more cephalad than the opening into the oesophagus. In some cases, a mucosal tag at the oesophageal stoma acts as a valve. Both these anatomical features minimise the inhalation of secretions and explain the low morbidity in these patients for long periods of time. It is this variant of the " $H$ " type fistula one would expect to see in the adult group as it is compatible with prolonged survival. A useful terminology in the adult is " $N$ " type fistula. This depicts more accurately the anatomical features and has some prognostic significance for the behaviour of the fistula.

I would like to thank Dr C Lomas for permission to report this case and for his support and the Department of Radiology for their diagnostic assistance.

\section{References}

${ }^{1}$ Waterston DJ, Carter REB, Aberdeen E. Oesophageal atresia: tracheoesophageal fistula. Lancet 1962;1:819-22.

${ }^{2}$ Holder T, Cloud DT, Lewis JE, Pilling GP. Esophageal atresia and tracheoesophageal fistula. Pediatrics 1964; $34: 542-9$.

${ }^{3}$ Sundar B, Guiney EJ, O’Donnell B. Congenital H-type tracheo-oesophageal fistula. Arch Dis Child 1975;50: 862-3.

4 Negus VE. Esophagus from a middle aged man, showing a congenital opening into the trachea. $J$ Laryngol Otol $1929 ; 44: 184$

${ }^{5}$ McKinney R. Tracheo-oesophageal fistula, probably congenital, in a woman 58 years of age. Ann Otol Rhinol Laryngol 1933;42:1237-9.

- Krausey B. Congenital tracheoesophageal fistula without oesophageal atresia with resultant asphyxial death. $\mathrm{Br}$ Med J 1953;1:1433.

7 Caldwell KPS. Congenital tracheoesophageal fistula in the adult. J Int Coll Surg 1954;22:387-90.

${ }^{8}$ Mathey J, Lemoine A. Tracheal diverticulum and congenital oesophagotracheal fistula without oesophageal atresia. Thorax 1954;9:106-11.

${ }^{9}$ Demong CV, Grown JB, Heitzman GC. Congenital tracheoesophageal fistula without atresia of the oesophagus. Am Surg 1959;25:156-62.

${ }^{10}$ Ferguson CC, Schoemperlin CB. Congenital tracheoesophageal fistula in an adult. Ann Surg 1959;149:582-5.

1 Lansden FT, Falor WA. Congenital esophagorespiratory fistula in the adult. $J$ Thorac Cardiovasc Surg 1960;39: 246-51.

12 Zack BJ, Owen MP. Congenital tracheoesophageal fistula in the adult. Arch Surg 1969;95:674-7.

13 Tenta LT, Ford LH. Congenital $H$ type TE fistula in a young adult. Arch Otolaryngol 1967;85:675-9.

${ }^{14}$ Bertelsen S. Congenital oesophageal-tracheal fistulas in the adult. Scand J Thorac Cardiovasc Surg 1970;4:80-2.

15 Acosta JL, Battersby JS. Congenital tracheoesophageal fistula in the adult. Ann Thorac Surg 1974;17:51-7.

${ }^{16}$ Stephens RW, Lingeman RE, Lawson LJ. Congenital tracheoesophageal fistulas in adults. Ann Otol Rhinol Laryngol 1976;85:613-7.

17 Bedard P, Girvan DP, Shandling B. Congenital H type tracheoesophageal fistula. J Paediat Surg 1974;9:663-8.

${ }^{18}$ Buker RH, Cox WA, Pauling FW, Seitter G. Complications of congenital tracheoesophageal fistula. Am J Surg 1972; 124:705-10. 